\title{
Chiral triazolium salts and ionic liquids: from the molecular design vectors to their physical properties through specific supramolecular interactions
}

\author{
Raul Porcar, ${ }^{[a]}$ Nicolás Ríos-Lombardía, ${ }^{[b]}$ Eduardo Busto, ${ }^{[b]}$ Vicente Gotor-Fernández, ${ }^{[b]}$ Jose \\ Montejo-Bernardo, ${ }^{[c]}$ Santiago García-Granda, ${ }^{[c]}$ Santiago V. Luis, ${ }^{[a]}$ Vicente Gotor, ${ }^{[b]}$ Ignacio \\ Alfonso, ${ }^{*[d]}$ and Eduardo García-Verdugo*[a]
}

\begin{abstract}
An exhaustive experimental study based on X-ray, NMR, ATR FTIR and Raman spectroscopy as well as theoretical calculations is reported in order to understand how the noncovalent intermolecular contacts are fundamental to explain structure/properties relationships and allowing us to correlate a basic macroscopic property (melting point, $\mathrm{Tm}$ ) with the structural variables of a family of enantiopure 1,4-dialkyl-1,2,4triazolium salts. The effect of different structural vectors such as ring size, substituent spatial disposition,
\end{abstract}

substitution on the oxygen, anion nature or N-4-triazole alkylation on the intermolecular interactions of these chiral salts of a well-defined 3D structure is reported. The non-covalent intermolecular contacts mainly implicating the triazoliun $\mathrm{H} 3$ atom are fundamental to explain structure/properties

\section{Keywords: polymeric supramolecular fluids • triazolium salts • Chiral Ionic liquid}

relationships and therefore the physical properties of these new chiral salts, rather than simple anion-cation interactions. Overall, our findings highlight the importance of the specific supramolecular interactions for the understanding of the physical properties of triazolium salts and ionic liquids. [a] Dr. E. García-Verdugo, Prof. S. V. Luis, Dr. R. Porcar Departamento de Química Inorgánica y Orgánica Universitat Jaume

Av. de Vicent Sos Baynat s/n, Castellón de la Plana 12071, España Fax: +34 964728214; Tel: +34 96472875 E-mail: cepeda@uji.es

[b] Dr. N. Ríos-Lombardía, Dr. E. Busto, Dr. V. Gotor-Fernández, Prof. V. Gotor

Departamento de Química Orgánica e Inorgánica Instituto Universitario de Biotecnología de Asturias Universidad de Oviedo

Avenida Julián Clavería s/n, Oviedo 33006 (Asturias), España Fax: +34 985103448

[c] Prof. J. Montejo-Bernardo, Prof. S. García-Granda Departamento de Química Física y Analítica Universidad de Oviedo-CINN

Avenida Julián Clavería s/n, Oviedo 33006 (Asturias), España

[d] Dr. I. Alfonso

Departamento de Química Biológica y Modelización Molecula Instituto de Química Avanzada de Cataluña

Consejo Superior de Investigaciones Científicas (IQAC-CSIC)

Calle Jordi Girona 18-26, Barcelona 08034, España

E-mail: ignacio.alfonso@iqac.csic.es

Supporting information for this article is available on the WWW under http://www.chemeurj.org/ or from the author.

\section{Introduction}

The synthesis and application of ionic liquids have increased exponentially in the last few years. ${ }^{1}$ One of the most interesting features of the ILs is their tuneable properties. ILs can be described as "polymeric supramolecular fluids", ${ }^{2}$ where their properties are defined by the network of coulombic and intermolecular interactions formed by the anions and cations. ${ }^{3}$ Although Coulomb forces are mainly the dominating interaction, the extended network of intermolecular interactions, based on the ability of cations and anions to present among others $\mathrm{H}$ bonds, $\pi-\pi$ or $\mathrm{C}-\mathrm{H} \cdots \pi$ interactions, etc. has strong implications on their three-dimensional (3D) organization and therefore on the properties of the ILs. ${ }^{4}$ Thus, in principle, the ILs can be prepared through a modular structural design in order to tune their self-organization allowing them to fulfill the characteristics needed for a given application.

In this context, some efforts have been made to develop chiral ionic liquids (CILs) ${ }^{6}$ and to exploit them as media either for chiral induction $^{7}$ or for enantiodifferentiation of chiral compounds. ${ }^{8}$. The introduction of chirality as a design vector is highly interesting as chilarity may define the self-organizable structure of the chiral salts in a privileged three-dimensional chiral lattice. We have recently reported a chemoenzymatic methodology for the synthesis of a new family of imidazolium CILs with a controlled structural diversity. ${ }^{9}$ Our results suggested that the chirality present in these enantiopure salts may define their self-organization and, therefore, a 
macroscopic property such as the melting point.

In general, the most common ILs are based on $N, N^{\prime}$ dialkylimidazolium cations. However, it has been reported that the introduction of a third nitrogen in the heterocycle impacts various physico-chemical properties relative to those of the analogous systems based on 1,3-imidazolium salts. ${ }^{10}$ The 1,2,4-triazolium salts present larger dipolar moment and different charge density than analogous imidazolium derivatives (see Figure 1). We have recently reported a synthetic methodology allowing the preparation of a new family of CILs in which the imidazole is replaced by a triazole ring as alternative molecular engineering design vector. ${ }^{11}$

In this paper, we report our further efforts to understand how the non-covalent intermolecular contacts are fundamental to explain structure/properties relationships and therefore the physical properties of this new family of enantiopure triazolium salts and ILs comparing their behavior with the one found for the analogous imidazolium salts. The introduction of the 1,2,4-triazole ring as a design vector together with others such as the ring size (five- or sixmembered ring), substitution on the oxygen $\left(\mathrm{R}^{\prime}=\mathrm{H}\right.$ or $\left.\mathrm{Ac}\right)$, the counterion $\left(\mathrm{X}^{-}=\mathrm{Br}^{-}, \mathrm{BF}_{4}^{-}\right.$, or $\left.\mathrm{NTf}_{2}^{-}\right)$, the triazole alkylating sidechain $(\mathrm{R}=\mathrm{Bn}, n-\mathrm{Bu}$, or $n$-Oct $)$ and the configuration at the two stereogenic centers and, in particular, the relative disposition (cis or trans) of the triazole and OR' groups on the cycloalkane ring may favor a different pattern in the anion-cation interactions leading to new family of chiral salts with modified macroscopic properties.

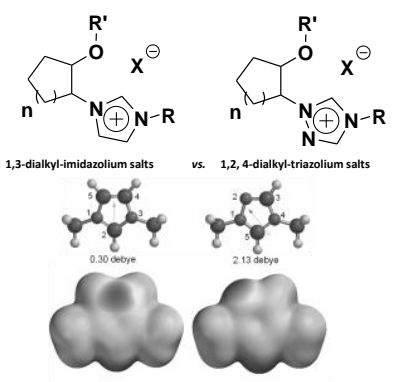

Figure 1. Triazolium units as additional design vectors employed in the synthesis of chiral salts. When compared with imidazolium, the triazolium ion has a larger dipole moment and different charge distribution.

\section{Results and Discussion}

Synthesis and phase transition (melting points) for the chiral triazolium salts: A series of chiral $\mathrm{N}$-alkylated 1,2,4-triazoles and their subsequent formation of quaternary 1,4-dialkyl-1,2,4triazolium salts was prepared by the combination of biocatalytic and chemical methods. ${ }^{11}$ The synthesis of enantiomerically pure salts was carried out by quaternization at the $N$-4 position of the different enantiopure triazoles using the corresponding alkyl or benzyl halide. Finally, the halide present in the initial triazolium salts was exchanged with different anions $\left(\mathrm{BF}_{4}^{-}\right.$or $\left.\mathrm{NTf}_{2}^{-}\right)$to give a family of more than 30 enantiopure chiral triazolium salts with significant structural diversity. ${ }^{12}$

The phase transitions (melting points, Tm) of the newly synthesized salts were measured by differential scanning calorimetry (DSC) in order to compare their physical properties. Thus, a dried sample of the corresponding salt was placed in a DSC pan and heated at $130{ }^{\circ} \mathrm{C}$ for $120 \mathrm{~min}$ to avoid the influence of the possible water in the series. Sample holders with perforated covers were used to allow the evaporation of water during thermal pretreatment. Three complete cycles of heating and cooling were then performed to clearly identify the corresponding phase transitions. All these operations were carried out under nitrogen. ${ }^{13}$
Table 1 illustrates some of the solid-liquid phase transitions of newly prepared triazolium salts, measured by DSC in the temperature range -65 to $400{ }^{\circ} \mathrm{C} .{ }^{14}$ The $\mathrm{T}_{\mathrm{m}}$ is an important parameter because it can be related with other properties of ionic liquids, like viscosity or conductivity. ${ }^{15}$

Table 1. Effect of the alkyl chain (Bn, But, or Oct) and counteranion $\left(\mathrm{Br}^{-}, \mathrm{BF}_{4}^{-}\right.$or $\left.\mathrm{NTf}_{2}^{-}\right)$ on the phase behaviour for some trans-chiral triazolium salts.

\begin{tabular}{|c|c|c|c|c|c|c|}
\hline \multirow{2}{*}{ CILs } & \multicolumn{3}{|c|}{$(S, S)$-trans-Cy5-OH- ${ }^{[\mathrm{a}]}$} & \multicolumn{3}{|c|}{$(S, S)$-trans-Cy6-OH- ${ }^{[\mathrm{a}]}$} \\
\hline & $\mathrm{Br}$ & $\mathrm{BF}_{4}$ & $\mathrm{NTf}_{2}$ & $\mathrm{Br}$ & $\mathrm{BF}_{4}$ & $\mathrm{NTf}_{2}$ \\
\hline Bn-Im- & 112 & -9 & -29 & 188 & 6 & -29 \\
\hline Bn-Tri- & 142 & 91 & -32 & 183 & 114 & -23 \\
\hline Bu-Tri & $\begin{array}{c}72^{[\mathrm{b}]} \\
131^{[\mathrm{c}]}\end{array}$ & $\begin{array}{c}78^{[\mathrm{b}]} \\
100^{[\mathrm{c}]}\end{array}$ & -53 & 192 & 145 & -45 \\
\hline Oct-Tri & 152 & $\begin{array}{c}-30^{[\mathrm{b}]} \\
60^{[\mathrm{b}]} \\
96^{[\mathrm{c}]}\end{array}$ & -54 & 176 & 79 & -47 \\
\hline
\end{tabular}

${ }^{\text {[a] }}$ Temperatures calculate for a heating rate of $5{ }^{\circ} \mathrm{C} \min ^{-1}$ at onset of the transitions of the third heating curve. All the transitions are referred from crystal to liquid otherwise is indicated. ${ }^{[b]}$ Crystal to liquid crystal. ${ }^{[c]}$ Liquid crystal to liquid.

In general, as observed for the imidazolium salts, cyclopentanolderived triazolium salts were found to have lower melting points than those derived from cyclohexanol. Regarding the counteranion effect, the original bromides cannot be considered as ILs. However, the exchange of bromide by a non-basic, non-coordinating anion such as $\mathrm{NTf}_{2}^{-}$led to a significant reduction on the melting points. Thus, the salts bearing $\mathrm{NTf}_{2}{ }^{-}$can be classified as room temperature ILs in all the cases. The exchange by $\mathrm{BF}_{4}^{-}$, however, produced only a moderate reduction on the $T_{m}$ being this reduction considerably less important than that observed for the analogous $\mathrm{Br}^{-} / \mathrm{BF}_{4}$ exchange for the imidazolium salts. ${ }^{9}$ Indeed, all the analogous imidazolium salts containing $\mathrm{BF}_{4}^{-}$can be considered as chiral RTILs $\left(\mathrm{T}_{\mathrm{m}}<100{ }^{\circ} \mathrm{C}\right)$, while the triazolium analogous are either organic salts $\left(\mathrm{T}_{\mathrm{m}}>100{ }^{\circ} \mathrm{C}\right)$ or ILs with high melting points $\left(\mathrm{T}_{\mathrm{m}} \sim 80-100{ }^{\circ} \mathrm{C}\right)$. These results suggest the presence of a stronger specific intermolecular interaction between of the triazolium hydrogen atoms and the $\mathrm{BF}_{4}$, absent in the related imidazolium systems. The size and nature of the alkylating agent also has an influence on the observed $\mathrm{T}_{\mathrm{m}}$. The substitution of the benzyl group by an alkyl one (butyl or octyl) led to a lower reduction of the melting points than in the case of imidazolium derivatives. Similar behavior has been recently reported for non-chiral triazolium salts. ${ }^{16}$

Noteworthy, the (S,S)-trans-Cy5-OH-Bu-Tri-Br and (S,S)-transCy5-OH-Bu-Tri-BF4 salts showed a liquid crystal behavior, ${ }^{17}$ with melting processes occurring at 71.6 and $61.6^{\circ} \mathrm{C}$, respectively, and clearing processes being at 130.6 and $99.6{ }^{\circ} \mathrm{C}$, respectively (Figure 2 ). The presence of both the hydroxy group and the triazolium ring may enhance the intermolecular hydrogen bonding interactions between salts, therefore, favoring the mesomorphic structure of these compounds. ${ }^{18}$ The five member ring triazolium substitution seems to play an important role as an analogous behavior is not observed for the corresponding cyclohexanol derivatives. In a similar way, $(S, S)$-trans-Cy5-OH-Oct-Tri-BF 4 presented multiple phase transitions, which may be due to the presence of different metaphases favored by the presence of the longer $\mathrm{C} 8$-aliphatic chain (see DSC traces in SI).

Finally, the results obtained for the series of triazolium salts, in which the bromide anion and the benzyl group were kept as common structural elements, were carefully analyzed in order to obtain a deeper understanding of the effect of different structural modifications systematically introduced in ring size, substitution on the oxygen, and cis/trans geometry, over their phase transitions. 

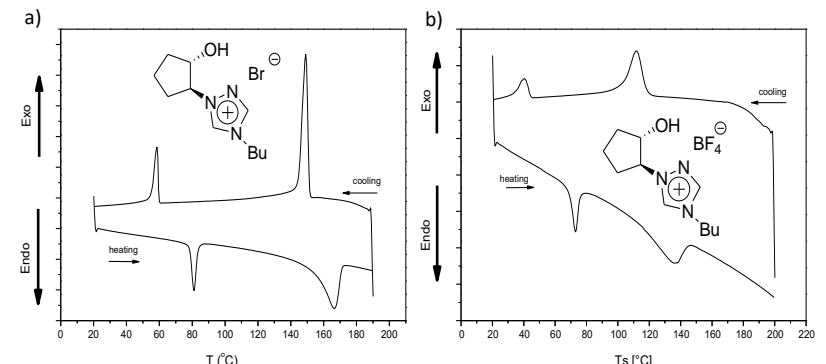

Figure 2. DSC curves of a) (S,S)-trans-Cy5-OH-Bu-Tri-Br and b) (S,S)-trans-Cy5-OH$\mathrm{Bu}-\mathrm{Tri}-\mathrm{BF}_{4}$ (third cooling and heating cycles)

Table 2 compares the results obtained for those compounds with the ones for the analogous imidazolium salts. Different trends can be highlighted: i) in both series (Tri and Im derivatives) the salts containing five-member rings gave lower melting points than those compounds bearing six-member rings; ii) Strikingly, significant differences were observed for the isomeric hydroxy cis- or transmolecular chiral salts derived either from triazolium or imidazolium salts. Indeed, the $\mathrm{T}_{\mathrm{m}}$ found for the triazolium cis-salts were higher than the trans one $\left[\mathrm{T}_{\mathrm{m}}\left(\right.\right.$ cis-OH-Tri) $>\mathrm{T}_{\mathrm{m}}$ (trans-OH-Tri)], while the opposite trend had been found for the analogous imidazolium salts $\left[\mathrm{T}_{\mathrm{m}}(\right.$ cis-OH- $\mathrm{Im})<\mathrm{T}_{\mathrm{m}}($ trans-OH-Im) $)$. The acylated triazolium salts showed, however, the opposite trend than the obtained for corresponding hydroxyl-triazolium salts. Thus, the $\left[\mathrm{T}_{\mathrm{m}}\right.$ (cis-OAc-Tri) $<\mathrm{T}_{\mathrm{m}}$ (trans-OAc-Tri)] being the same one found for the analogous acetylated imidazolium salts $\left[\left(\mathrm{T}_{\mathrm{m}}(\right.\right.$ cis-OAc- $\mathrm{Im})<\mathrm{T}_{\mathrm{m}}($ trans $-\mathrm{OAc}-$ $\mathrm{Im})]$. iii) the presence of either a $-\mathrm{OH}$ or -OAc functional group in the chiral salts also played an important role. In general, -OAc derivatives for both triazolium and imidazolium salts showed lower melting points than the corresponding alcohols.

These changes on the observed melting point illustrate the importance of the selection of either triazolium/imidazolium as a design vector as well as the significant role played by the cis/trans geometry of the $\mathrm{OH} / \mathrm{OAc}$ group relative to either the triazolium or imidazolium ring to define the macroscopic properties of the corresponding chiral salts.

Table 2. Phase transition (melting points in Celsius degrees) for a family of enantiopure chiral triazolium salts with controlled structural modifications compared with the corresponding imidazolium salts.

\begin{tabular}{|c|c|c|c|c|}
\hline IL-X & $\begin{array}{l}(S, S) \text {-trans- } \\
\text { Cy5-OH-Bn }\end{array}$ & $\begin{array}{c}(R, R) \text {-trans-Cy5- } \\
\text { OAc-Bn }\end{array}$ & $\begin{array}{c}(R, S) \text {-cis-Cy5- } \\
\text { OH-Bn }\end{array}$ & $\begin{array}{c}(R, S)-c i s-\mathrm{Cy} 5- \\
\text { OAc-Bn }\end{array}$ \\
\hline $\begin{array}{c}\text { Tri- } \\
\mathrm{Br}\end{array}$ & 142 & 79 & 183 & 13 \\
\hline $\begin{array}{c}\mathrm{Im}- \\
\mathrm{Br}\end{array}$ & 112 & 19 & 14 & 21 \\
\hline IL-X & $\begin{array}{l}(S, S) \text {-trans- } \\
\text { Cy6-OH-Bn }\end{array}$ & $\begin{array}{c}(R, R) \text {-trans-Cy6- } \\
\text { OAc-Bn }\end{array}$ & $\begin{array}{c}(R, S)-c i s-\mathrm{Cy} 6- \\
\mathrm{OH}-\mathrm{Bn}\end{array}$ & $\begin{array}{c}(R, S)-c i s-\mathrm{Cy} 6- \\
\text { OAc-Bn }\end{array}$ \\
\hline $\begin{array}{l}\text { Tri- } \\
\mathrm{Br}\end{array}$ & 183 & 143 & 203 & 27 \\
\hline $\begin{array}{c}\mathrm{Im}- \\
\mathrm{Br}\end{array}$ & 188 & 182 & 156 & 44 \\
\hline
\end{tabular}

In order to understand all the above mentioned trends, different tools were used to establish clear structure/properties relationships:

Theoretical calculations: Molecular modeling: For the molecular modeling studies, minimizations were carried out with cations and anions, as well as with the ionic pairs on model systems (bearing a Me group at N4). Local minima were detected by semiempirical PM3 conformational searches. These minima were fully optimized at the B3LYP/6-31+G* DFT level of theory, including frequence analysis to ensure they are minima of energy and thus, the global minima were located in every case. Besides, the interaction energy (E int., Table 3) between cation and anion was computed at the B3LYP/6-31+G* DFT level of theory as follows:

$$
\mathrm{E}_{\text {int. }}=\mathrm{E}_{(\text {(isolated ionic pair) }}-\left[\mathrm{E}_{\text {(isolated cation) }}+\mathrm{E}_{(\text {(isolated anion) }}\right]
$$

The interaction energies showed some interesting trends. For instance, the acylation of the $\mathrm{OH}$ group decreases the $\mathrm{E}$ int (see entries 2 vs. 3 , and 5 vs. 6 , Table 3) in good agreement with the experimental tendencies found for the observed $T_{m}$ values. Inspection of the optimized geometries indicated that this fact is due to a favorable $\mathrm{OH} \cdots$ anion $\mathrm{H}$-bond interaction. On the other hand, the anion-cation interaction also correlates well with the basicity of the corresponding anion (see entries 6,7 and 8) as usually proposed for ionic liquids. The calculations, however, failed to explain two facts: the higher melting of the triazolium tetrafluoroborate salts as compared to the corresponding imidazolium ones and the different trends for the cis/trans isomers of either triazolium or imidazolium derivatives. For the hydroxyl triazolium derivatives, we observed that the theoretical cation-anion interactions are stronger for the trans derivatives, while the melting temperatures are higher for the cis than for the trans. This suggests that the anion-cation interactions within the ion pairs cannot fully explain the experimentally observed trends of melting temperatures of the corresponding triazolium salts. Thus, we hypothesized that higher order intermolecular interactions could be playing an important role in these cases (see next sections).

Table 3. Interaction energies $(\mathrm{kcal} / \mathrm{mol})$ for the computed $\left(\mathrm{B} 3 \mathrm{LYP} / 6-31+\mathrm{G}^{*}\right)$ mode chiral triazolium salts.

\begin{tabular}{ccc}
\hline Entry & Chiral triazolium salts & -E int. $(\mathrm{kcal} / \mathrm{mol})$ \\
\hline 1 & $(R, S)$-cis-Cy5-OH-Me-Tri-Br & 89.47 \\
2 & $(S, S)$-trans-Cy5-OH-Me-Tri-Br & 93.31 \\
3 & $(R, R)$-trans-Cy5-OAc-Me-Tri-Br & 89.55 \\
4 & $(R, S)$-cis-Cy6-OH-Me-Tri-Br & 88.64 \\
5 & $(S, S)$-trans-Cy6-OH-Me-Tri-Br & 101.77 \\
6 & $(R, R)$-trans-Cy6-OAc-Me-Tri-Br & 88.19 \\
7 & $(S, S)$-trans-Cy6-OH-Me-Tri-BF & 86.23 \\
8 & $(S, S)$-trans-Cy6-OH-Me-Tri-NTf & 78.90 \\
\hline
\end{tabular}

Single crystal X-ray diffraction studies: In some cases, the triazolium salts formed single crystals suitable for X-ray diffraction analysis. Crystallographic analysis may provide a direct insight into the spatial relationship between the cations and anions and establish the basis for an enhanced understanding of structure/properties relationship of our chiral salts. ${ }^{19}$ Thus, the X-ray diffraction study of the compound $(S, S)$-trans-Cy5-OH-Bn-Tri-Br was performed and the results are shown in Figure 3. ${ }^{11}$ Several structural features must be mentioned. Interestingly, the five member ring shows an envelope conformation with the two substituents in pseudoaxial position (Figure 3A). This apparently high energy conformation must be stabilized by the non-covalent interactions of the cation within the crystal cell (Figure 3B). These interactions are easily understood by the careful analysis of the anion-cation contacts. Every bromide is surrounded by four cations which form a tight binding pocket within the crystal structure (Figure 3C). The $\mathrm{Br}$ anion sets one $\mathrm{H}$-bond with one $\mathrm{OH}$ (Table 4), two $\mathrm{H}$-bonds with two C-H of two different triazolium cations (Table 4), two cationic pi $\cdots$ anion interactions with two triazolium cations (centroid of triazolium_1 $\cdots \mathrm{Br}: \mathrm{d}=3.529 \AA$, angle $=84.2^{\circ}$; centroid of triazolium_2 $\cdots \mathrm{Br}: \mathrm{d}=3.594 \AA$, angle $=76.7^{\circ}$ ) and a weaker pi $\cdots$ anion contact with the benzyl aromatic ring (centroid of phenyl $\cdots$ Br: $d=4.729 \AA$ ̊). 20 On the other hand, every organic cation sets the same corresponding respective interactions with four bromide anions (Figure 3D). 

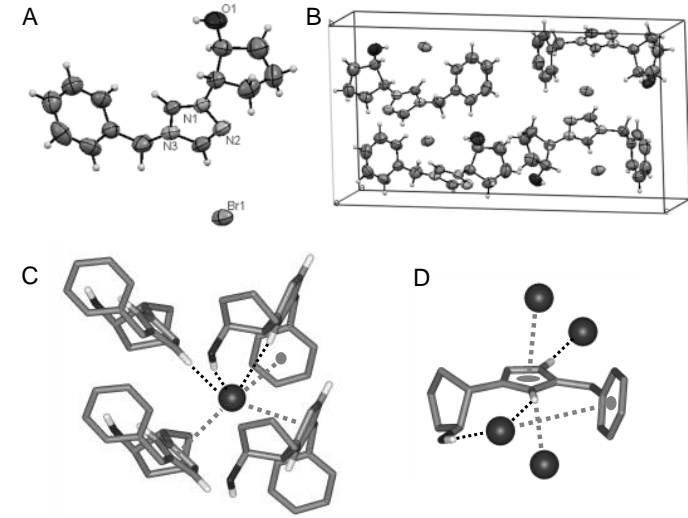

Figure 3. A) Molecular structure of the salt (S,S)-trans-Cy5-OH-Bn-Tri- Br observed in the solid state by $\mathrm{X}$ ray diffraction analysis of single crystals. B) Crystal packing. C-D) Highlighted interactions observed either around every bromide anion $\mathrm{C}$ or around every organic cation D. In C-D) non-polar C-H atoms are omitted for clarity. In C-D the Hbonds are shown as black dashed lines, while anion $\cdots \pi$ interactions are shown as grey dotted lines.

Table 4. Geometrical parameters for the selected H-bond interactions observed by X-ray diffraction of single crystals of triazolium salts. Numbers in parentheses correspond to standard deviations in the last significant figure.

\begin{tabular}{|c|c|c|c|c|c|}
\hline Triazolium & trans-Cy5 & cis-Cy6 & trans-Cy6 & trans-Cy6 & $\begin{array}{l}\text { trans- } \\
\text { Cy6 }\end{array}$ \\
\hline $\begin{array}{c}\text { Anion (A) } \\
\text { T meas. / K }\end{array}$ & $\begin{array}{c}\mathrm{Br}^{-} \\
298\end{array}$ & $\begin{array}{c}\mathrm{Br}^{-} \\
298\end{array}$ & $\begin{array}{c}\mathrm{Br}^{-} \\
298\end{array}$ & $\begin{array}{c}\mathrm{Br}^{-} \\
100\end{array}$ & $\begin{array}{c}\mathrm{BF}_{4}^{-} \\
100\end{array}$ \\
\hline $\mathrm{d}(\mathrm{OH} \cdots \mathrm{A}) / \AA$ & $2.4999^{[b]}$ & $2.5024^{[a]}$ & $2.34^{[a]}$ & $2.42^{[\mathrm{a}]}$ & $\begin{array}{l}1.96^{[\mathrm{f}]} \\
2.36^{[\mathrm{f}]}\end{array}$ \\
\hline$>(\mathrm{O}-\mathrm{H} \cdot \cdots \mathrm{A}){ }^{\circ}$ & 162.8 & 172.8 & 178 & 172 & $\begin{array}{l}157 \\
140\end{array}$ \\
\hline $\mathrm{d}(\mathrm{C} 5 \mathrm{H} \cdot \cdots \mathrm{A}) / \AA$ & $2.9194^{[\mathrm{b}]}$ & $2.8614^{[\mathrm{c}]}$ & $2.61^{[\mathrm{a}]}$ & $2.66^{[\mathrm{a}]}$ & 2.10 \\
\hline$>(\mathrm{C} 5 \mathrm{H} \cdots \mathrm{A}){ }^{\circ}$ & 144.8 & 145.9 & 153 & 157 & 160 \\
\hline $\mathrm{OH} \cdot \cdots \mathrm{A} \cdot \cdots \mathrm{HC} 5$ & intra & inter & intra & intra & Inter \\
\hline $\mathrm{d}(\mathrm{C} 3 \mathrm{H} \cdot \cdots \mathrm{A}) / \AA$ & $2.6752^{[\mathrm{a}]}$ & $2.7399^{[\mathrm{d}]}$ & $2.74^{[\mathrm{e}]}$ & $2.86^{[\mathrm{h}]}$ & $2.13^{[\mathrm{i}]}$ \\
\hline$>(\mathrm{C} 3 \mathrm{H} \cdot \bullet \mathrm{A}))^{\circ}$ & 173.1 & 172.5 & 174 & 169 & 166 \\
\hline $\begin{array}{c}\text { crystal label for } \\
\mathrm{OH} / \mathrm{C} 5 \mathrm{H} / \mathrm{C} 3 \mathrm{H}\end{array}$ & $\mathrm{H} 1 / \mathrm{H} 6 / \mathrm{H} 7$ & $\mathrm{H} 1 / \mathrm{H} 7 / \mathrm{H} 8$ & $\mathrm{H} 1 / \mathrm{H} 7 / \mathrm{H} 8$ & $\mathrm{H} 1 / \mathrm{H} 7 / \mathrm{H} 8$ & $\begin{array}{c}\mathrm{H} 1 / \mathrm{H} 7 / \\
\mathrm{H} 8\end{array}$ \\
\hline
\end{tabular}

We were also able to obtain crystals of $(R, S)$-cis-Cy6-OH-BnTri-Br suitable for X-ray diffraction analysis. ${ }^{11}$ The cyclohexane ring shows a chair conformation with the triazolium equatorial and the $\mathrm{OH}$ axial (Figure 4A). Similar cation-anion interactions were found within the crystal lattice, either for an anion surrounded by the cations or for the cation surrounded by anions (Figure 4C,D). For instance, we observed several $\mathrm{H}$-bonds implicating the bromide anion: $\mathrm{O}-\mathrm{H} \cdots \mathrm{Br}, \mathrm{C} 3-\mathrm{H} \cdots \mathrm{Br}$ and $\mathrm{C} 5-\mathrm{H} \cdots \mathrm{Br}$ (Table 4). Also in this case, we observed anion-pi contacts with both the triazolium and the benzyl rings: centroid of triazolium_1 $\cdots \mathrm{Br}(\mathrm{d}=3.504 \AA$, angle: $\left.81.8^{\circ}\right)$, centroid of triazolium_ $2 \cdots \mathrm{Br}\left(\mathrm{d}=3.552 \AA\right.$, angle: $\left.80.2^{\circ}\right)$; centroid of phenyl $\cdots \mathrm{Br}(\mathrm{d}=4.704 \AA)$. The most important difference between both crystal structures is the disposition of the $\mathrm{H}$-bond interactions. In the (S,S)-trans-Cy5-OH-Bn-Tri-Br derivative, the same bromide is $\mathrm{H}$-bonded to the $\mathrm{OH}$ and one of the triazolium protons $(\mathrm{H} 5)$ of the same cation, while for $(R, S)$-cis-Cy6$\mathrm{OH}-\mathrm{Bn}-\mathrm{Tri}-\mathrm{Br}$ the $\mathrm{H} 5$ and $\mathrm{OH}$ protons of a given molecule are $\mathrm{H}-$ bonded to different bromides (compare Figures 3D and 4D). This is a very important feature, since it could give rise to different behaviors in the melting process, as it would require the breaking of these intermolecular interactions (see below).

Another important feature arose by comparing the H-bonding geometries implicating $\mathrm{H} 3$ and $\mathrm{H} 5$ hydrogen atoms of the triazolium moieties (see Table 4). In both crystal structures, the $\mathrm{C} 3-\mathrm{H} \cdots \mathrm{Br}$ distances are shorter and the corresponding angles wider than those for $\mathrm{C} 5-\mathrm{H} \cdots \mathrm{Br}$ contacts. These data suggest that the hydrogen bond of the $\mathrm{Br}$ is stronger with $\mathrm{H} 3$ than with $\mathrm{H} 5$ in the solid state, and points to the importance of intermolecular interactions for the stability of the triazolium salts.

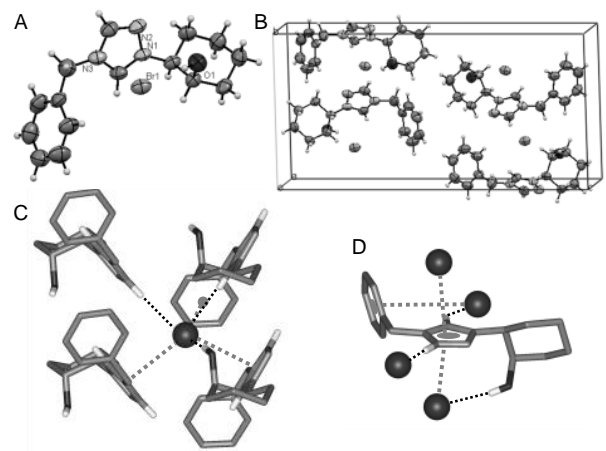

Figure 4. A) Molecular structure of the salt $(R, S)$-cis-Cy6-OH-Bn-Tri- $\mathrm{Br}$ observed in the solid state by $\mathrm{X}$ ray diffraction analysis of single crystals. B) Crystal packing. C-D) Highlighted interactions observed either around every bromide anion $\mathrm{C}$ ) or around every organic cation D). In C-D) non-polar C-H atoms are omitted for clarity. In C-D) the H-bonds are shown in black dashed lines, while anion $\cdots \pi$ interactions are shown as grey dotted lines.

The differences between cis and trans dispositions of the substituents of the ring are even more evident by comparing crystal structures containing the same cyclic moiety. Fortunately, we were also able to get crystals of the $(S, S)$-trans-Cy6-OH-Bn-Tri-Br derivative (Figure 5). The cyclohexane ring of the cation also adopts a chair conformation, in this case with both substituents in equatorial disposition. This allows the $\mathrm{OH}$ and the $\mathrm{C} 5 \mathrm{H}$ hydrogens of the same molecule to set simultaeous $\mathrm{H}$-bonding interactions with the same bromide anion (Figures 5A, 5C and 5D). This geometrical disposition is in very good agreement with the one found in gas phase by theoretical calculations (see Supp. Inf.) and highlights the importance of the ion pairing through $\mathrm{OH}$ and $\mathrm{H} 5$ hydrogens of the same cation. Besides, the $\mathrm{H}$-bonds between the $\mathrm{Br}$ anion and both the $\mathrm{OH}$ and $\mathrm{C} 5 \mathrm{H}$ are shorter for the trans than for the cis isomer (Table 4), while the the H-bonds between the $\mathrm{Br}$ anion and $\mathrm{C} 3 \mathrm{H}$ is similar for both conformation (cis and trans, Table 4). This suggests a stronger ion pairing (intramolecular H-bonding) for the trans stereoisomer, as obtained by theoretical calculations. On the other hand, an additional $\mathrm{C} 3-\mathrm{H} \cdots \mathrm{Br} \mathrm{H}$-bond and several anion-pi contacts can be proposed, forming a binding site for the anion which very much resembles the one observed for the cyclopentane derivative (compare figures 5C and 3C). Correspondingly, also the triazolium cation displays a similar environment formed by the surrounding bromide anions (compare figures 5D and 3D). Thus, considering the cis/trans disposition of the chiral centers, the main differences found in the solid state are based on the ability of the anion to simultaneously interact with the $\mathrm{OH}$ and the $\mathrm{H} 5$ hydrogens of the same cation, which is possible in the trans isomer but not in the corresponding cis derivative. This fact introduces differences in the bromide binding site for the cis/trans isomers of the cyclohexane derivative (compare figures $4 \mathrm{C}$ and $5 \mathrm{C}$ ), which must be the source for the differences in their corresponding melting temperatures. These observations prompted us to hypothesize that the anion-cation contacts in an isolated ion-pair would be stronger in the trans than in the cis isomers, as observed in the theoretical calculations (see previous section) and in solution by NMR and FT-IR (see below). Accordingly, the higher meltings found for the cis isomers must be due to strong interactions connecting different ion pairs (what we have called intermolecular interactions, see below) either through the $\mathrm{H} 3$ or the $\mathrm{H} 5$ hydrogen of the triazolium heterocycle. 


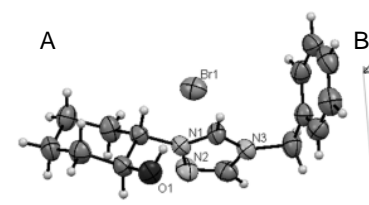

C
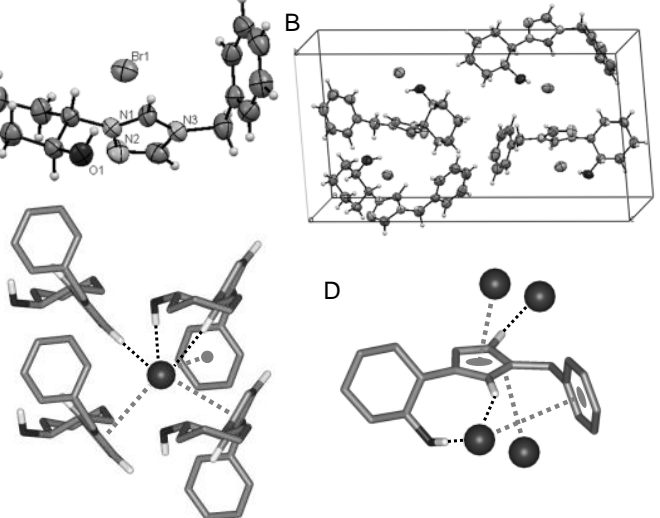

Figure 5. A) Molecular structure of the salt $(S, S)$-trans-Cy6-OH-Bn-Tri-Br observed in the solid state by $\mathrm{X}$ ray diffraction analysis of single crystals. B) Crystal packing. C-D) Highlighted interactions observed either around every bromide anion $\mathrm{C}$ ) or around every organic cation D). In C-D) non-polar C-H atoms are omitted for clarity. In C-D) the $\mathrm{H}$-bonds are shown in black dashed lines, while anion $\cdots \pi$ interactions are shown as grey dotted lines.

After an intensive and systematic work, we were also able to get crystals of one of the corresponding tetrafluoroborate salts, namely $(S, S)$-trans-Cy6-OH-Bn-Tri-BF 4 , which also shed some light onto the strong impact of the anion in the supramolecular assembly of the ionic network. However, we had to collect the diffraction at low temperature to get satisfactory data for the accurate refinement of the structure, which already suggests a less efficient packing of the crystal cell with $\mathrm{BF}_{4}$. Thus, for a fair comparison, we repeated the diffraction of the bromide salt also at low temperature (Table 4). Interestingly, the cationic moiety of both salts (the bromide and the $\mathrm{BF}_{4}$ ) displayed a very similar conformation regarding the cyclohexane, triazolium and benzyl moieties (compare figures 5A and 6A). Additionally, a similar disposition between the cation and the anion was also observed. However, an important difference was evident attending to the orientation of the hydroxyl groups in both structures. As previously stated, the $\mathrm{OH}$ in the bromide salt is forming a $\mathrm{H}$-bond with the anion also connected to the $\mathrm{C} 5 \mathrm{H}$ of the same cation (what we call intramolecular H-bonds). On the other hand, the cationic moiety of the salt with $\mathrm{BF}_{4}$ sets $\mathrm{H}$-bonds through the $\mathrm{OH}$ and the $\mathrm{C} 5 \mathrm{H}$ with two different $\mathrm{BF}_{4}$ anions (what we have named intermolecular H-bonds). By comparing the binding sites of the anion (figures 5C and 6C) and the cation (figures 5D and 6D) we can conclude that the $\mathrm{Br} / \mathrm{BF}_{4}$ exchange strongly disrupt the anioncation interaction network. Strikingly, it turns out that the binding interactions of the trans- $\mathrm{BF}_{4}$ salt is quite similar to the corresponding cis isomer of the bromide salt (compare figures 6C and $4 \mathrm{C}$ for the anion, while figures $6 \mathrm{D}$ and $4 \mathrm{D}$ for the cation). This suggests that the presence of the $\mathrm{BF}_{4}$ anion favors the corresponding intermolecular contacts, explaining why the $\mathrm{Br} / \mathrm{BF}_{4}$ exchange produces a lower decrease of the melting temperature in the triazolium compounds, when compared with the imidazolium derivatives.
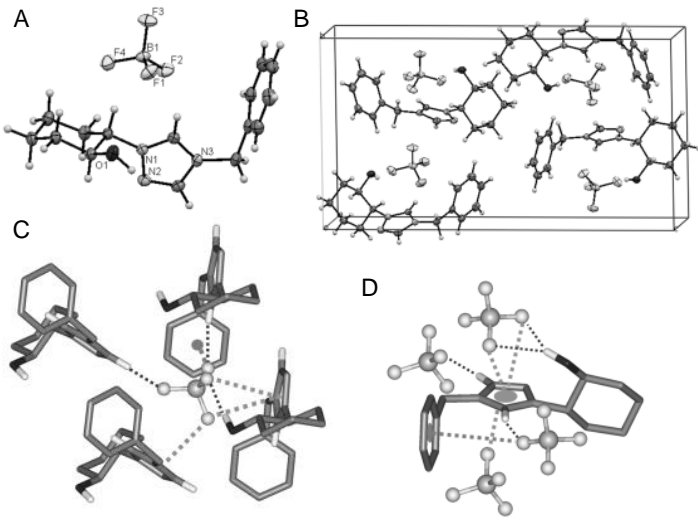

Figure 6. A) Molecular structure of salt the (S,S)-trans-Cy6-OH-Bn-Tri-BF 4 observed in the solid state by $\mathrm{X}$ ray diffraction analysis of single crystals. B) Crystal packing. C-D) Highlighted interactions observed either around every $\mathrm{BF}_{4}$ anion $\mathrm{C}$ ) or around every organic cation D). In C-D) non-polar C-H atoms are omitted for clarity. In C-D) the Hbonds are shown in black dashed lines, while anion $\cdots \pi$ interactions are shown as grey dotted lines.

A more accurate comparison of the effect of the anion is represented in figure 7 for the $\mathrm{Br}$ and $\mathrm{BF}_{4}$ structures of the trans isomer, both measured at the same temperature $(100 \mathrm{~K}$, see also Table 4). The H-bonding between the anion and $\mathrm{C} 3 \mathrm{H}$ is very similar in both salts, while the $\mathrm{OH} \cdots$ anion $\cdots \mathrm{HC} 5$ network is clearly different for both compounds, implicating just one triazolium moiety for the $\mathrm{Br}$ (intramolecular) and two different triazolium moieties for the $\mathrm{BF}_{4}$ (intermolecular). Besides, the $\mathrm{OH}$ in the $\mathrm{BF}_{4}$ salt is able to set two simultaneous $\mathrm{H}$-bonds with two $\mathrm{F}$ atoms of the anion, reflecting a strong interaction (see distances in table 4). Thus, starting from the same triazolium structure displaying very similar conformation, the presence of different anions produces important changes in the ionic H-bonding network, which can change from intramolecular to intermolecular. This must have a big impact in the physical properties of the triazolium salts, due to the supramolecular organization of the systems in a complicated network of interactions.

From all the data gathered in this section, several main conclusions can be extracted. First of all, the anion-cation contacts are mainly driven by the $\mathrm{OH}$ and $\mathrm{C} 5 \mathrm{H} / \mathrm{C} 3 \mathrm{H}$ hydrogen bonding, in addition to several anion-pi interactions. Within the same bromide anion for the $\mathrm{OH} \cdots \mathrm{Br} \cdots \mathrm{HC} 5$ network, the trans isomers displayed intramolecular contacts, while the cis derivatives set intermolecular interactions. The interactions through $\mathrm{C} 3 \mathrm{H}$ are always intermolecular, for obvious geometrical reasons. Finally, the anion exchange can completely change this behavior, although retaining basically the same structure for the cationic triazolium moiety.
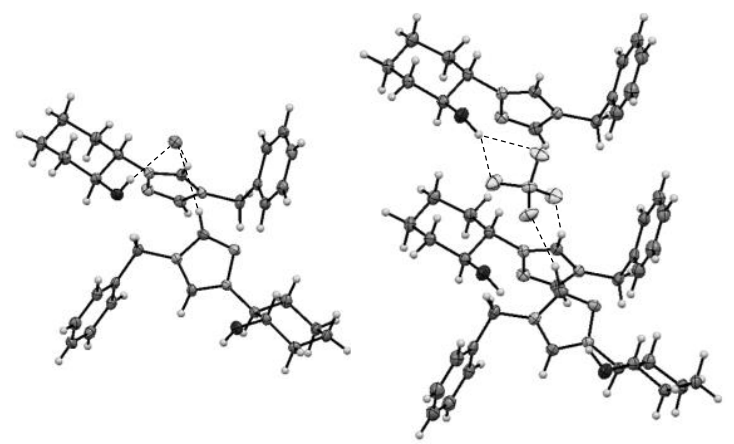

Figure 7. Comparison of the X-ray diffraction results (ORTEP representation) of the crystal structures of $(S, S)$-trans-Cy6-OH-Bn-Tri-X with $\mathrm{X}=\mathrm{Br}$ and $\mathrm{BF}_{4}$, both measured at $100 \mathrm{~K} . \mathrm{H}$-bonds are shown as black dashed lines. 
NMR studies of the triazolium salts: NMR studies, due to their extreme sensitivity on the micro-surrounding, may qualitatively provide new information on structuring effects related with the relative cis/trans configuration of the chiral centers. ${ }^{21}$ The presence of either isolated ion pair species or supramolecular aggregates corresponding to the cis/trans isomers of the $\mathrm{OH} / \mathrm{Br} / \mathrm{Bn}$ triazolium compounds (both Cy5 and Cy6) can be monitored by NMR studies. Accordingly, we used ${ }^{1} \mathrm{H}-\mathrm{NMR}$ in a non-polar solvent $\left(\mathrm{CDCl}_{3}\right)$ as a suitable technique to study the $\mathrm{H}$-bonding pattern at different overall concentrations. ${ }^{22}$ The establishing of H-bonding interactions would produce a shift of the implicated proton signals and the concentration dependence of the shifts would give us a picture of the aggregation process.

Our crystallographic studies (previous section) and the results obtained for the analogous imidazolium salts showed that the hydroxyl group of the cationic component tends to form a strong $\mathrm{H}$ bond with the anionic component. ${ }^{9}$ In the triazolium case, the anion could form two cooperative chelate-type H-bonds with the $\mathrm{OH}$ and the H5 proton of the heterocycle. However, this intramolecular interaction is impossible for $\mathrm{H} 3$, due to geometrical reasons. Thus, $\mathrm{H} 3$ is more suitable for setting intermolecular H-bonding contacts, leading to the aggregation between the ion pairs into a supramolecular structure (Scheme 1). According to this model, we can propose the formation of different H-bonding patterns, depending on the concentration of the sample. At high concentration, supramolecular oligomers can be proposed, where the $\mathrm{H} 3$ proton would be driving the 3D network of intermolecular interactions (see Scheme 1). As far as we dilute the sample, these aggregates would disassemble to lead to the corresponding isolated ion pair, where the bromide would be interacting with the $\mathrm{OH}$ and the $\mathrm{H} 5$ proton, but not with $\mathrm{H} 3$. Finally, if we dilute the sample even more, we could dissociate the ion pair to the corresponding solvated ions. $^{23}$

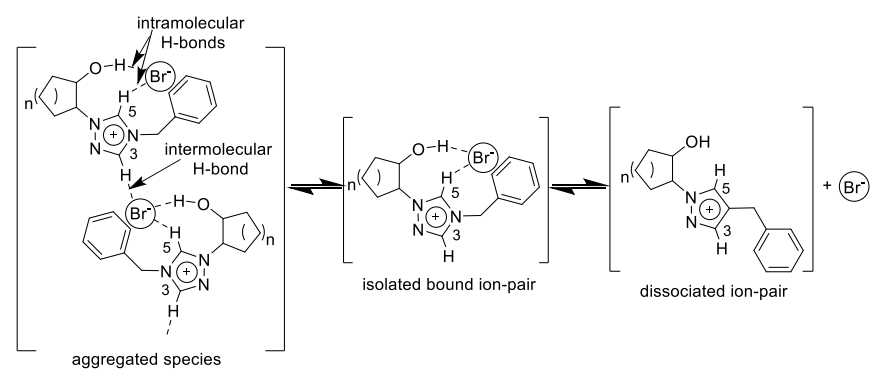

Scheme 1.

The ${ }^{1} \mathrm{H}$ NMR spectrum of $(R, S)$-cis-Cy5-OH-Bn-Tri-Br was acquired $\left(\mathrm{CDCl}_{3}, 500 \mathrm{MHz}, 298 \mathrm{~K}\right)$ at different concentrations (Figure 8A). Several proton signals were affected by the concentration of the sample, mainly those corresponding to the triazolium moiety (H3 and $\mathrm{H} 5)$ and the benzylic residue (aromatic protons and $\mathrm{NCH}_{2} \mathrm{Ph}$ ). The compound showed a low solubility in chloroform, being the measured concentration of the soluble species in a saturated sample ca. $10 \mathrm{mM}$ (see Figure 8A). This observation suggested a considerable aggregation tendency of this compound. At $4 \mathrm{mM}$, mainly $\mathrm{H} 3$ and $\mathrm{NCH}_{2} \mathrm{Ph}$ move upfield and the signals from the benzyl group start to broaden. Below $1 \mathrm{mM}$, the signal for $\mathrm{H} 5$ slightly moves upfield and also appreciably broadens. More interestingly, the chemical environment of the benzyl residue dramatically changes. Thus, all the aromatic protons appear as a broad singlet and the methylene of the carbon attached to the triazolium changes from an $\mathrm{AB}$ quartet to a singlet upon dilution. The loss of the anisochrony of these protons is associated to the breaking of the $\mathrm{H} 5 \cdot \mathrm{Br}$ hydrogen bond, which allows the triazolium to freely rotate and, thus, the chirality of the cyclopentyl moiety is no longer transferred to the benzyl group. The experiments suggest that above $10 \mathrm{mM}$ the compound strongly associates through intermolecular interactions, mainly involving $\mathrm{H} 3$. In the range 1-10 $\mathrm{mM}$, the compound exists in solution as an equilibrium mixture of different species (as depicted in Scheme 1). Below $1 \mathrm{mM}$, the ion pair seems to dissociate, as observed from the changes in $\mathrm{H} 5$ and the signals from the benzyl residue.

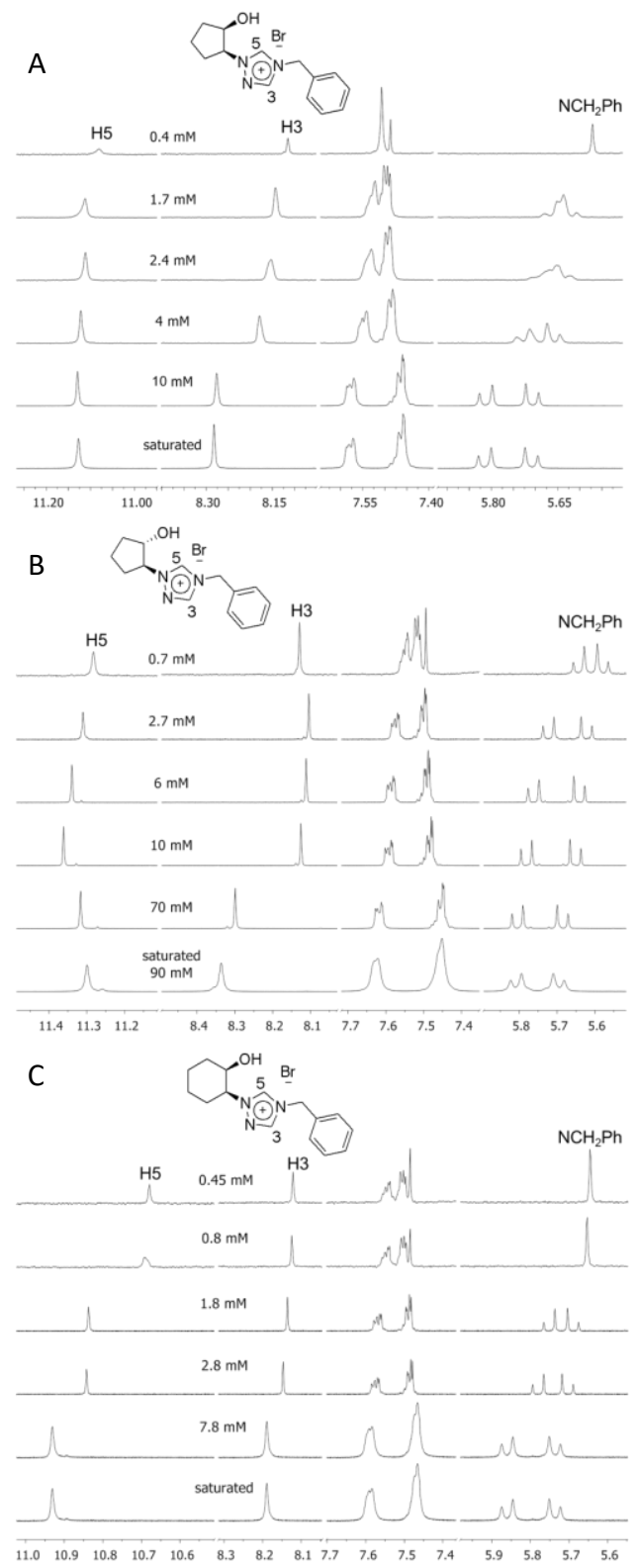

Figure 8. Selected regions of the ${ }^{1} \mathrm{H}$ NMR spectra $\left(\mathrm{CDCl}_{3}, 500 \mathrm{MHz}, 298 \mathrm{~K}\right)$ at different overall concentrations for (A) $(R, S)$-cis-Cy5-OH-Bn-Tri-Br, (B) $(S, S)$-trans-Cy5-OH$\mathrm{Bn}-\mathrm{Tri}-\mathrm{Br}$, and $(\mathrm{C})(R, S)$-cis-Cy6-OH-Bn-Tri-Br.

According to this, we could shift the equilibrium between aggregated species and isolated ion pairs by increasing the temperature (because this would increase the entropy of the system). Besides, since the two implicated protons (H5 and $\mathrm{H} 3$ ) are electronically interconnected, the breaking of the H-bond implicating H3 (intermolecular) would strengthen the H-bond of H5 (intramolecular). This is exactly what we observed by acquiring the ${ }^{1} \mathrm{H}$ NMR of a $10 \mathrm{mM}$ sample (where aggregated species are present) of $(R, S)$-cis-Cy5-OH-Bn-Tri-Br at different temperatures (see Figure 9). 


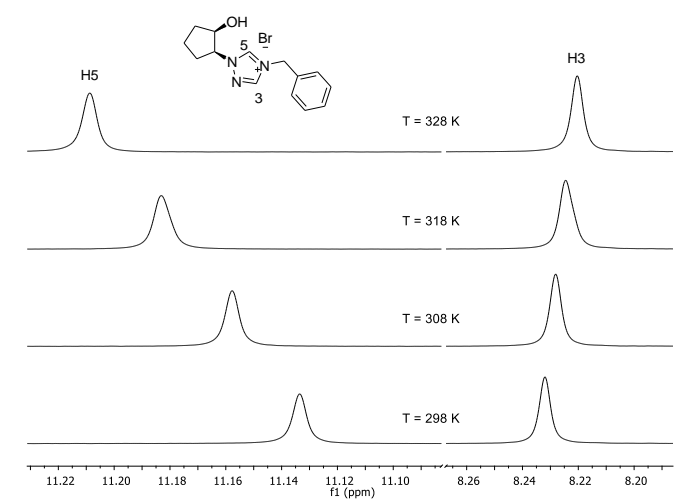

Figure 9. Temperature dependence of $\mathrm{H} 5$ and $\mathrm{H} 3$ proton signals of $(R, S)$-cis-Cy5-OHBn-Tri-Br (10 mM in $\left.\mathrm{CDCl}_{3}, 500 \mathrm{MHz}\right)$.

As far as the temperature is increased, a downfield shift of $\mathrm{H} 5$ (stronger H-bond) and a slight upfield shift of $\mathrm{H} 3$ (weaker H-bond) were observed. These results confirm that $\mathrm{H} 3$ is mainly involved in the intermolecular interactions, while $\mathrm{H} 5$ can be associated with the intramolecular ones. Besides, the temperature behaviour of $\mathrm{H} 5$ suggests a strongly electrostatic nature of the $\mathrm{H} 5 \cdots \mathrm{Br}_{\text {contacts. }}{ }^{24}$

The first striking observation when performing the same study with the corresponding trans diastereomer [ $(S, S)$-trans-Cy5-OH-BnTri-Br, Figure $8 \mathrm{~B}$ ] was the higher solubility of this compound in chloroform. Thus, the saturated sample of $(S, S)$-trans-Cy5-OH-BnTri-Br showed a measured concentration of ca. $90 \mathrm{mM}$, almost one order of magnitude higher than the cis isomer. This already suggested a lower trend to aggregate of the trans diastereomer. Besides, it allowed the observation of the ${ }^{1} \mathrm{H}$ NMR signals in a higher concentration range. Thus, when going from $90 \mathrm{mM}$ to 10 $\mathrm{mM}$ concentration, $\mathrm{H} 3$ dramatically moves upfield $(\sim 0.23 \mathrm{ppm})$ and a similar behaviour, although in a lower extent, is observed for the signals of the benzyl residue. However, H5 experiences a slight downfield shift, which is in agreement with the transition from supramolecular aggregates to isolated ion-pairs, which would weaken $\mathrm{H} 3 \cdots \mathrm{Br} \mathrm{H}$-bonds and strengthen $\mathrm{H} 5 \cdots \mathrm{Br}$ H-bonds. When moving from $10 \mathrm{mM}$ to below $1 \mathrm{mM}$, a slight shielding of $\mathrm{H} 5$ is observed. The benzylic methylene also moves upfield but these protons retain their anisochrony. These data suggest that the ion pair interaction is retained below $1 \mathrm{mM}$. For a fair comparison between the cis and the trans isomers, the variation of the chemical shift of $\mathrm{H} 3$ proton was monitored over a similar concentration range in both cases $(2-10 \mathrm{mM})$. Interestingly, the cis isomer showed an upfield shift of $0.13 \mathrm{ppm}$ upon dilution, while for the trans it was $0.03 \mathrm{ppm}$ over the same concentration range. This difference supports the stronger aggregation ability for the cis isomer through interactions involving $\mathrm{H} 3$.

Overall, by taking together the data obtained for both isomers, we extracted three main conclusions: i) the cis isomer shows a much higher propensity to aggregation; ii) the intermolecular interactions mainly implicate $\mathrm{H}$ bonding through $\mathrm{H} 3$; iii) the isolated ion pair, which is stabilized through $\mathrm{H} 5 \cdots \mathrm{Br} \mathrm{H}$-bonding, is stronger with the trans than with the cis isomer. This last conclusion is in good agreement with the interaction energies obtained by theoretical calculations, performed with the isolated ion pairs.

In order to complete the ${ }^{1} \mathrm{H}$ NMR study, the same experiments were also performed with the cyclohexane derivatives, which rendered similar conclusions (Figures $8 \mathrm{C}$ and 10A). Moreover, the differences between cis/trans derivatives were even more marked in this case. For example, the concentration of a saturated sample of $(R, S)$-cis-Cy6-OH-Bn-Tri-Br was roughly $8 \mathrm{mM}$, while the trans isomer could be recorded at $150 \mathrm{mM}$ without signs of the formation of large aggregates (no turbidity) in the NMR tube. Besides, also in this case, the cis isomer showed free rotation of the benzyltriazolium moiety at concentrations below $1 \mathrm{mM}$, while the trans derivative displayed clear anisochrony of the $\mathrm{NCH}_{2} \mathrm{Ph}$ signals at 0.8 $\mathrm{mM}$. This means, once again, that the anion-cation interaction within the isolated ion pair is much stronger in the trans derivative, which is in perfect agreement with the theoretical calculations. The $\mathrm{H} 3$ proton moves upfield with dilution in both cases, which supports its implication in the intermolecular aggregation process. However, the behaviour of H5 is very different when comparing the cis/trans isomers of the six-member ring. In the cis compound, H5 resonates at lower chemical shift as far as the sample is diluted, both in the range of aggregation (from 8 to $1 \mathrm{mM}$, observed from the $\mathrm{AB}$ quartet of benzylic methylene) and in the range of the dissociation of the ion-pair (below $1 \mathrm{mM}$, singlet for the same methylene). This suggests that, in this case, $\mathrm{H} 5$ is implicated in both (intermolecular and intramolecular) interactions. On the contrary, the same proton (H5) in the trans isomer moves downfield when the sample is diluted (from 150 to $2 \mathrm{mM}$ and, specially, below $2 \mathrm{mM}$ ), suggesting that the $\mathrm{H}$-bond interaction between $\mathrm{H} 5$ and bromide anion is strengthen by dilution. This observation is in accordance with our previous assumption that, as far as the intermolecular interactions are eliminated (or reduced), the ion pair interactions are favoured, which is clearly observable by the behaviour of $\mathrm{H} 3 / \mathrm{H} 5$ protons of (S,S)-trans-Cy6-OH-Bn-Tri-Br. The implication of the H5 proton in intermolecular interactions for the cis isomer and the clear intramolecular H-bonding of the same proton in the trans derivative is in a remarkable agreement with the data obtained in the solid state of both compounds (see previous section), reinforcing our proposal for the overal picture of the aggregation process.

We also used NMR spectroscopy for the study of the effect of the anion in the aggregation proccess, selecting the $(S, S)$-trans-Cy6$\mathrm{OH}-\mathrm{Bn}$-Tri derivative since it showed the best solubility allowing the acquisition of the ${ }^{1} \mathrm{H}$ NMR spectra in a abroader concentration range (Figure 10). The observed trends are in agreement with the basicity of the anions and with the observed melting temperatures for the corresponding salts. The chemical shift of the H5 proton is more affected by the nature of the anion, appearing downfield for the more basic anion $\left(\mathrm{Br}>\mathrm{BF}_{4}>\mathrm{NTf}_{2}\right)$. In all the cases, the behavior of $\mathrm{H} 5 / \mathrm{H} 3$ protons can be explained following our proposal, where $\mathrm{H} 3$ produces the aggregation bettwen ion pairs and $\mathrm{H} 5$ is maily implicated in the ion pairing contacts, which addionally reinforces our model. 


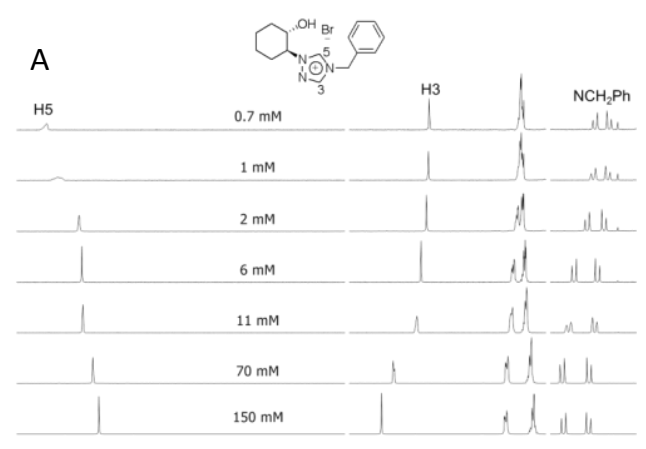

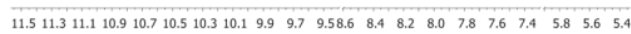

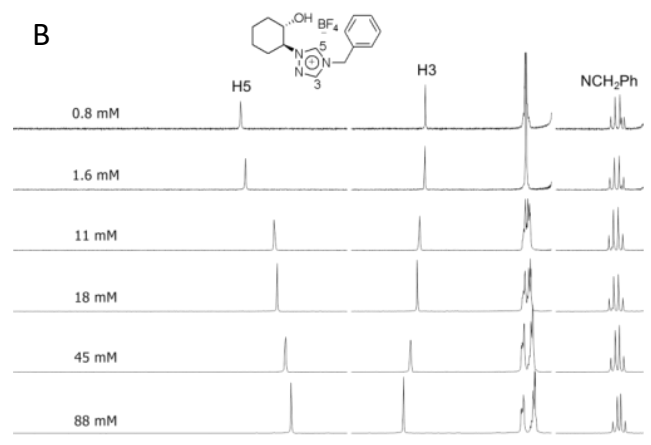

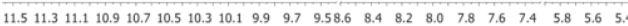

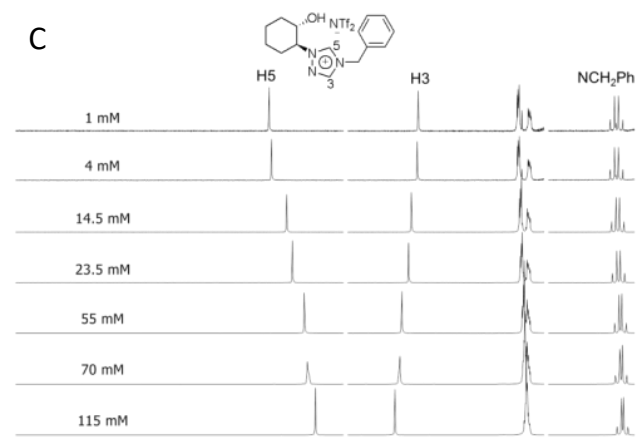

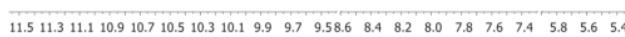

Figure 10. (A-C) Effect of the anion on the aggregation: Selected regions of the ${ }^{1} \mathrm{H}$ NMR spectra $\left(\mathrm{CDCl}_{3}, 500 \mathrm{MHz}, 298 \mathrm{~K}\right)$ at different overall concentrations for $(S, S)$ trans-Cy6-OH-Bn-Tri-X for $(\mathrm{A}) \mathrm{X}=\mathrm{Br}$, (B) $\mathrm{X}=\mathrm{BF}_{4}$ and $(\mathrm{C}) \mathrm{X}=\mathrm{NTf}_{2}$.

FTIR-ATR-and Raman Spectroscopy: Additional spectroscopic studies were performed using FTIR-ATR and Raman microscopy. Vibrational spectroscopy studies are a versatile tool mainly providing information over the $\mathrm{CH} \cdots$ anion intermolecular interactions established by the triazolium-based cations in both bulk liquid and solid compounds and in solution. ${ }^{25}$ Figure 11 presents the ATR FT-IR spectra of the (S,S)-trans-Cy5-OH-Bn-Im-Br and those of the related cis and trans triazolium salts in the range between $3500-2800 \mathrm{~cm}^{-1}$. As it can be seen, the introduction of an additional nitrogen atom in the heterocycle induces significant changes in the $\mathrm{CH}$ spectra region. Indeed, by going from imidazolium to triazolium salts, the number of peaks were significantly reduced. In the first case, at least three vibrational bands observed, related with the stretching modes for the $\mathrm{C}(2) \mathrm{H}$ and $\mathrm{C}(4,5) \mathrm{H}$ at 3145.8, 3128.9, and $3101.5 \mathrm{~cm}^{-1}$, which form H-bonds on both sides of the imidazolium defining the $3 \mathrm{D}$ structure of the pure salts. ${ }^{9}$ They are reduced, in the case of the trans-triazolium salt, to a single broad band, which is significantly red-shifted at $3088.9 \mathrm{~cm}^{-1}$ and can be associated with the corresponding stretching modes of the $\mathrm{C}(3)-\mathrm{H}$ and $\mathrm{C}(5)-\mathrm{H}$ of the triazolium H-bonded with the anion. The $\mathrm{C}-\mathrm{H}$ bond is weakened upon formation of a $\mathrm{C}-\mathrm{H} \cdots \mathrm{X}$ hydrogen bond and, therefore, the frequency of its stretching vibration decreases ${ }^{26}$ Besides, the bands related with $\mathrm{CH}$ stretching vibrations of the benzene ring, at the range of $3090-3000 \mathrm{~cm}^{-1}$, are also clearly shifted toward lower wavenumbers in the case of the triazolium salts. This may well respond to the intermolecular specific $\pi-\pi$ interaction between the aromatic rings, and the $\pi \cdots$ anion contact between the bromide and the benzyl or triazolium aromatic rings observed in the crystal structure of the triazolium salt (see Figure 3 and 4). All those close interactions lead to a more intimate intermolecular association justifying, at some extent, the higher melting point of the triazolium vs. the imidazolium salts. Furthermore, the ATR FT-IR spectra provide additional information about the $\mathrm{OH} \cdots \mathrm{X}$ interactions. Indeed, the band corresponding to the $\mathrm{OH}$ band for the transimidazolium salts appears at lower frequencies than for the related trans-triazolium salts $\left(3272.1\right.$ vs. $\left.3291.9 \mathrm{~cm}^{-1}\right)$. This fact seems to suggest that the higher meltings observed for the triazolium salts are mainly the result of the synergic contribution of hydrogen-bonding driven by $\mathrm{C}(3)-\mathrm{H}$ and $\mathrm{C}(5)-\mathrm{H}$ and $\pi-\pi$ or $\mathrm{C}-\mathrm{H} \cdots \pi$ bonding involving benzyl and triazolium aromatic rings, playing the contribution of the $\mathrm{OH} \cdots \mathrm{X}$ interactions, in this case, a less important role.

Figure 11 allows a comparison of the spectra of the cis/trans triazolium salts. The bands related with the stretching vibrational modes of $\mathrm{C}(3)-\mathrm{H}$ and $\mathrm{C}(5)-\mathrm{H}$ for the cis-triazolium salts are shifted towards lower wavenumber than those observed for the trans-isomer (3080.7 and $3059.5 \mathrm{~cm}^{-1}$ vs. a broad band at $3088.9 \mathrm{~cm}^{-1}$ ). The peak associated with the $\mathrm{OH}$ vibration mode for the cis-triazolium salts is also red-shifted compared to trans-derivative $\left(3279.3 \mathrm{~cm}^{-1}\right.$ vs. $3291.9 \mathrm{~cm}^{-1}$ ). Similar trends were also found for the Cy6-triazolium salts. All these data suggest a more efficient interaction between anions and the cations for the cis isomer justifying their higher melting points.

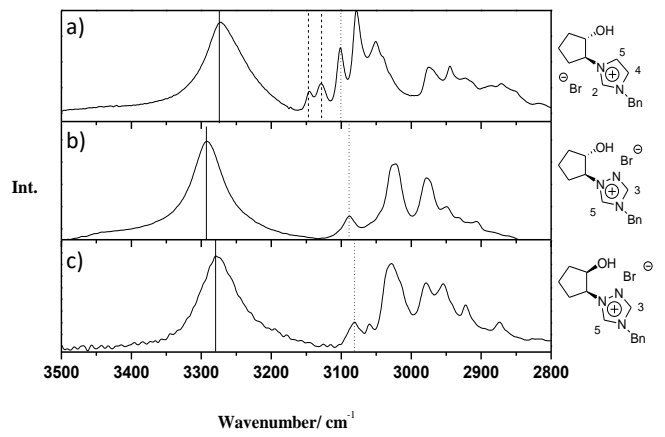

Figure 11. Infrared spectra of the $\mathrm{CH}$ stretching region from 3500 to $2800 \mathrm{~cm}^{-1}$. a) $(S, S)$ trans-Cy5-OH-Bn-Im-Br; b) (S,S)-trans-Cy5-OH-Bn-Tri-Br; c) $(R, S)$-cis-Cy5-OH-BnTri-Br.

This point was further confirmed when the Raman spectra of $(R, S)$-cis-Cy6-OH-Bn-Tri-Br and (S,S)-trans-Cy6-OH-Bn-Tri-Br were also studied. Figure 12 shows the region ranging from 1600 $1500 \mathrm{~cm}^{-1}$, which contains the C-C stretching vibration modes of benzene and triazolium rings. Thus, the spectra corresponding to the cis-Cy6-OH isomer presents both new and red-shifted bands at 1608.6, 1590.0 and 1582.9 compared with those found for transCy6-OH bromide salts at 1611.5 , and $1590.6 \mathrm{~cm}^{-1}$. In a similar way, the $\mathrm{C}-\mathrm{N}$ stretching mode of the triazolium ring is sensitive to the cis/trans substitution (1480-1400 $\mathrm{cm}^{-1}$ region). Hence, the transisomer shows Raman peaks at 1457.7, 1451.7, 1403.5 and 1428.0 $\mathrm{cm}^{-1}$, whereas for the corresponding cis-isomer bands appear at 1452.94, 1442.04, and $1424.8 \mathrm{~cm}^{-1}$. This red-shift of the bands suggests a stronger association of the cis-triazolium salts. 


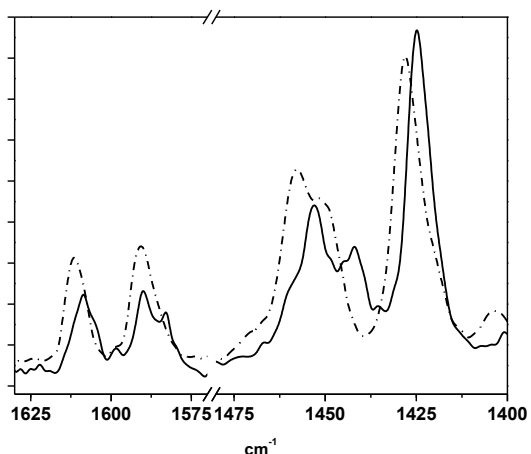

Figure 12. Raman spectra of $(R, S)$-cis-Cy6-OH-Bn-Tri-Br (solid line) and (S,S)-transCy6-OH-Bn-Tri-Br (dotted line) in the $1630-1570 \mathrm{~cm}^{-1}$ and $1480-1400 \mathrm{~cm}^{-1}$ regions.

Finally the IR spectrum of a thin film of $(R, S)$-cis-Cy6-OH-BnTri- $\mathrm{Br}$ was also measured. A solution of the salt in $\mathrm{CDCl}_{3}(1 \mathrm{mM})$ was deposited onto an FT-IR ATR sample holder and spectra were continuously recorded during the slow evaporation of the solvent (Figure 13). The first spectrum did not show any appreciable bands corresponding to the triazoliums salts due to the high dilution. However, the increase of concentration as a result of solvent evaporation, yielded peaks showing a monotonic red-shift of the characteristics bands. Hence, the slow evaporation of the solvent is accompanied with an increase of the intermolecular interactions. The establishment of the H-bonds can be appreciated by the $\mathrm{OH} \cdots \mathrm{X}$ band, which is becoming narrower and red-shifted from $3350 \mathrm{~cm}^{-1}$ to $3314 \mathrm{~cm}^{-1}$ and the change in the $\mathrm{C}(3)-\mathrm{H}$ and $\mathrm{C}(5)$ adsorption peaks, which shifted from $3091 \mathrm{~cm}^{-1}$ to $3087.2 \mathrm{~cm}^{-1}$. These values are very close to the ones obtained for the bulk solid salts 3088.4 $\mathrm{cm}^{-1}$ suggesting the incipient formation of aggregates in solution, in qualitative agreement with our findings by NMR spectroscopy.

Considering all these experimental results, we propose an explanation for the different trends observed for the melting temperatures of cis/trans derivatives of triazolium salts compared with those corresponding to the imidazolium salts (see Table 2). In the case of the imidazolium derivatives, the intramolecular cationanion interactions were playing a major role, apart from the hydrophobic and van der Waals contacts. In the case of the triazolium salts, the proton $\mathrm{H} 3$ strongly participates in the interactions with the anion due to its increased acidity. As a result of the geometrical disposition of $\mathrm{H} 3$ with respect to the $\mathrm{OH}$ group, $\mathrm{H} 3 \cdots \mathrm{Br}$ interactions would occur through intermolecular contacts. On the other hand, $\mathrm{H} 3$ and $\mathrm{H} 5 \mathrm{H}$-bonding abilities should be correlated. The cis derivatives display a lower tendency to form intramolecular $\mathrm{H} 5 \cdots \mathrm{Br}$ interactions (as observed by the theoretical calculations and NMR), which makes intermolecular $\mathrm{H} 3 \cdots \mathrm{Br}$ contacts much more efficient (as observed from the IR, Raman and NMR and $X$ ray diffraction studies). Thus, in the case of the triazolium, the intermolecular contacts make the cis-salts more stable (higher $\mathrm{Tm}$ ) than the trans isomers.

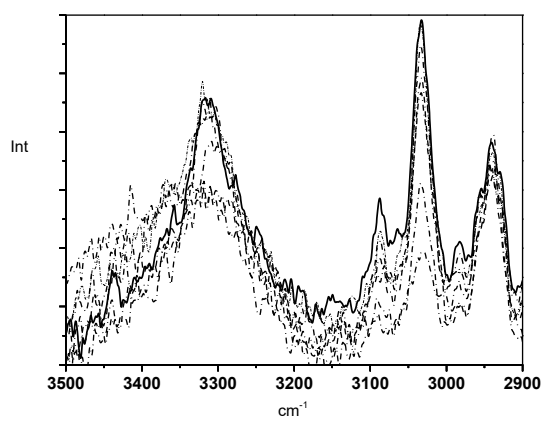

Figure 13. FTIR-ATR adsorption spectra of the evaporation of $(R, S)$-cis-Cy6-OH-BnTri-Br in $\mathrm{CDCl}_{3}(1 \mathrm{mM})$ in the $3500-2900 \mathrm{~cm}^{-1}$.

\section{Conclusion}

In this paper, we have studied, in detail, the origin of differences found for different chiral triazolium salts as a function of a variety of structural vectors such as ring size, substituent spatial disposition, substitution on the oxygen, anion nature or $\mathrm{N}$-4-triazole alkylation on the intermolecular interactions of these chiral salts. These vectors are able to induce structural directionality ("entropic effect") on the chiral organic salts mainly through well-defined networks of supramolecular synergetic intermolecular interactions. Our results suggest that the higher meltings observed for the triazolium salts are mainly the result of the contribution of hydrogen-bonding driven by $\mathrm{C}(3)-\mathrm{H}$ and $\mathrm{C}(5)-\mathrm{H}$ bonding involving side chains and triazolium aromatic rings, playing the contribution of the $\mathrm{OH} \cdots \mathrm{X}$ interactions, in comparison with the analogous imidazolium salts, a less important role. The non-covalent intermolecular contacts mainly implicating the triazolium $\mathrm{H} 3$ atom are fundamental to explain structure/properties relationships and therefore the physical properties of these new chiral salts, rather than simple anion-cation interactions.

\section{Acknowledgements}

Financial support by Ministerio de Ciencia e Innovación (MICINN CTQ 2011-28903, CTQ2009-14366-C02, CTQ2008-04415 and, CTQ2008-04309, MAT2006-01997 \& MAT2010-15094 and BANCAIXA (P1-1B-2009-58) are acknowledged. V.G.-F. (Ramón y Cajal Program) thank MICINN for personal funding. N.R-L. thanks FICYT for a pre-doctoral fellowship.

[1] a) N. V. Plechkova, R. D. Rogers, K. R. Seddon, Ionic liquids: From knowledge to application; American Chemical Society Symposium Series 1030: Washington DC, 2009; b) P. Wasserscheid, T. Welton, Ionic Liquids in Synthesis, Wiley-VCH, Weinheim, 2007; c) R. D. Rogers, G. A. Voth, Acc. Chem. Res. 2007, 40,1077-1078 (Ionic Liquids special issue).

[2] P. A. Z. Suarez, S. Einloft, J. E. L. Dullius, R. F. de Souza, J. Dupont, J. Chim Phys. Phys.-Chim. Biol. 1998, 95, 1626-1639.

[3] a) A. Mele, C. D. Tran, S. H. de Paoli Lacerda, Angew. Chem. Int. Ed. 2003, 42 , 4364-4366; b) M. Antonietti, D. Kuang, B. Smarsly, Y. Zhou, Angew. Chem. Int. Ed. 2004, 43, 4988-4992; c) J. Dupont, J. Braz. Chem. Soc. 2004, 15, 341 350 .

[4] K. Fumino, T. Peppel, M. Geppert-Rybczyńska, D. H. Zaitsau, J. K. Lehmann, S. P. Verevkin, M. Köckerling, R. Ludwig, Phys. Chem. Chem. Phys. 2011, 13, 14064-14075.

[5] a) N. Sun, H. Rodríguez, M. Rahman, R. D. Rogers, Chem. Commun. 2011, 47 , 1405-1421; b) N. V. Plechkova, K.R. Seddon, Chem. Soc. Rev. 2008, 37, 123 150

[6] a) K. Bica and P. Gaertner, Eur. J. Org. Chem. 2008, 19, 3235-3250; b) A. Winkel, P. V. G. Reddy, R. Wilhelm, Synthesis, 2008, 7, 999-1016; c) X. Chen, X. Li, A. Hu, F. Wang, Tetrahedron: Asymmetry, 2008, 19, 1-14; d) A. D. Headley, B. Ni, Aldrichimica Acta, 2007, 40, 107-117; e) C. Baudequin, D. 
Brjgeon, J. Levillain, F. Guillen, J.-C. Plaquevent, A.-C. Gaumont, Tetrahedron: Asymmetry, 2005, 16, 3921-3945; f) J. Ding, D. W. Armstrong, Chirality, 2005, 17, 281-292; g) C. Baudequin, J. Baudoux, J. Levillain, D. Cahard, A.-C. Gaumont, J.-C. Plaquevent, Tetrahedron: Asymmetry, 2003, 14 3081-3093.

[7] a) M. H. G. Prechtl, J. D. Scholten, B. A. D. Neto, J. Dupont, Curr. Org. Chem 2009, 13, 1259-1277; b) S. Luo, L. Zhang, J.-P Cheng, Chem. Asian J. 2009, 4, 1184-1195; c) X. Lijin, Y. Bing, D. Limin, T. Weijun, Prog. Chem. 2010, 22 , 1254-1273.

[8] a) W. Bi, M. Tian, K. H. Row Analyst. 2011, 136, 379-387; b) Z. Ma, L. Zhang L. Lin, P. Ji, X. Guo, Biomed. Chromatogr. 2010, 24, 1332-1337; c) S. L. De Rooy, M. Li, D. K. Bwambok, B. El-Zahab, S. Challa, I. M. Warner, Chirality, 2011, 23, 54-62; d) A. Winkel, R. Wilhelm, Eur. J. Org. Chem. 2010, 82, $5817-$ 5824 .

[9] a) E. Busto, V. Gotor-Fernández, N. Ríos-Lombardía, E. García-Verdugo, I Alfonso, S. García-Granda, A. Menéndez-Velázquez, M. I. Burguete, S. V. Luis V. Gotor, Tetrahedron Lett., 2007, 48, 5251-5254; b) N. Ríos-Lombardía, E. Busto, V. Gotor-Fernández, V. Gotor, R. Porcar, E. García-Verdugo, S. V. Luis, I.; Alfonso, S. García-Granda, A. Menéndez-Velázquez, Chem. Eur. J. 2010, 16 , 838-847.

[10] A. R. Katritzky, S. Singh, K. Kirichenko, M. Smiglak, J. D. Holbrey, W. M Reichert, S. K. Spear, R. D. Rogers, Chem. Eur. J. 2006, 12, 4630-4641.

[11] N. Ríos-Lombardía, R. Porcar, E. Busto, I. Alfonso, J. Montejo-Bernardo, S. García-Granda, V. Gotor, S. V. Luis, E. Garcia-Verdugo, V. Gotor-Fernández ChemCatChem. 2011, 3, 1921-1928.

[12] The nomenclature of imidazolium/triazolium salts is defined by seven descriptors: the first one includes the absolute configuration of $\mathrm{C} 1$ and $\mathrm{C} 2$ at the cycloalkyl ring [for instance: $(S, S)$-]. The relative configuration at these carbon atoms is reported by the second descriptor trans or cis [for instance: $(S, S)$-trans] The size of the cycloalkyl ring is described through the use of the terms Cy5 for cyclopentane rings and $\mathrm{Cy} 6$ for cyclohexane rings [for instance: $(S, S)$-trans$\mathrm{Cy} 5]$. The fourth descriptor indicates the presence of $\mathrm{OH}$ or $\mathrm{OAc}$ at $\mathrm{C} 2$ of the cycloalkyl ring [for instance: $(S, S)$-trans-Cy5-OH-]. The nature of the alkyl chain at $\mathrm{N} 4$ of the triazolium moiety is indicated by the use of Bn (for benzyl), $\mathrm{Bu}$ (for butyl), or Oct (for octyl) [for instance: $(S, S)$-trans-Cy5-OH-Bu-]. Finally, the term Im/Tri refers to the central core of imidazolium/triazolium, while the last descriptor refers to the specific anion included in the structure [for instance: $(S, S)$-trans-Cy5-OH-Bu-Tri-Cl].

[13] See supporting information for a completed list of Yields and Tm of all the ionic liquid prepared in this work.

[14] The higher temperature was adjusted attending the thermal stability of each salt under consideration.
[15] J.P. Hallett, T.Welton, Chem. Rev. 2011, 111, 3508-3576.

[16] D. Meyer, T. Strassner, J. Org. Chem. 2011, 76, 305-308.

[17] K. Binnemans, Chem. Rev. 2005, 105, 4148-4204.

[18] J. Y. Z. Chiou, J. N. Chen, J. S. Lei, I. J. B. Lin, J. Mater. Chem. 2006, 16, 2972-2977.

[19] P. M. Dean, J. M. Pringle, D. R. MacFarlane, Phys. Chem. Chem. Phys. 2010 12, 9144-9153

[20] a) D. Quiñonero, C. Garau, C. Rotger, A. Frontera, P. Ballester, A. Costa, P. M Deyà, Angew. Chem. Int. Ed. 2002, 41, 3389-3392; b) G. Gil-Ramírez, E. C. Escudero-Adán, J. Benet-Buchholz, P. Ballester, Angew. Chem. Int. Ed. 2008, 47, 4114-4118; c) B. P. Hay, V. S. Bryantsev, Chem. Commun. 2008, 21, $2417-$ 2428.

[21] V. P. Ananikov, Chem. Rev. 2011, 111, 418-454.

[22] C. S. Consorti, P. A. Z. Suarez, R. F. de Souza, R. A. Burrow, D. H. Farrar, A. J. Lough, W. Loh, L. H. M. da Silva, J. Dupont, J. Phys. Chem. B, 2005, 109 , 4341-4349.

[23] ${ }^{1} \mathrm{H}-\mathrm{NMR}$ spectra of selected examples in dry, acid-free $\mathrm{CDCl} 3$ at different concentrations. In order to exactly know the concentration of the dissolved and observable species (some turbidity was observed for concentrated samples, see below) a small amount of dichloromethane $(10 \mathrm{mM})$ was added as an internal standard. The observed turbidity is due to the formation of suspended aggregates which are fairly soluble and unobservable by NMR due to relaxation-produced broadening. Thus, for concentrated samples, the prepared nominal concentration was higher than the concentration of the observed species (saturated samples) as checked by the comparison of the integral of the corresponding signals of the compounds and the internal standard.

[24] The high acidity of H5 can be further demonstrated because under certain conditions (catalytic amounts of acid or base in deuterated solvent) H5 undergoes proton deuterium exchange.

[25] a) A. Wulf, K. Fumino, R. Ludwig, Angew. Chem. Int. Ed.. 2010, 49, 449-453; b) A. Yokozeki, D. J. Kasprzak, M. B. Shiflett, Phys. Chem. Chem. Phys. 2007, 9, 5018-5026.

[26] A. V. Iogansen, Spectrochim. Acta Part A, 1999, 55, 1585-1612.

Received: ((will be filled in by the editorial staff))

Revised: ((will be filled in by the editorial staff))

Published online: ((will be filled in by the editorial staff)) 